\title{
APONTAMENTOS SOBRE O ART. 1.147 DO CÓDIGO CIVIL: A CLÁUSULA DE NÃO RESTABELECIMENTO
}

\section{Pedro Pereira Lopes ${ }^{1}$}

Resumo: Este artigo tem por objetivo transmitir apontamentos sobre a norma contida no art. 1.147 do Código Civil de 2002, sem correspondência na legislação anterior. A pretensão não é exaurir o tema, mas definir os institutos essenciais para a adequada compreensão da cláusula de não restabelecimento, mediante referência não apenas à jurisprudência, mas também aos comercialistas mais referendados. Confia-se em que este estudo fornecerá ao leitor os subsídios necessários para diferir conceitos por vezes confundidos, tais quais, o de aviamento e clientela, assim como o de sociedade empresarial e estabelecimento.

Palavras-chave: Estabelecimento. Cláusula de não restabelecimento. Concorrência desleal. Aviamento. Clientela.

\section{APPOINTMENTS ABOUT ART. 1.147 OF THE CIVIL CODE: THE CLAUSE OF NON-RESTORATION}

Abstract: This paper's objetive is to transmit some notes about the norm deriving from art. 1,147 of the Civil Code of 2002, that did not match in the previous legislation. The pretension is not to exhaust the theme, but to define the essential institutes for an adequate understanding of the non-reinstatement clause, according to the concepts formulated by doctrine and jurisprudence. It is hoped that this paper can provide the reader the necessary subsidies to defer concepts that are sometimes confused, such as the one of goodwill and clientele, as well as that of a business society and establishment.

Keywords: Clause of non-reinstatement. Unfair competition. Goodwill. Clientele. Establishment.

\section{INTRODUÇÃo}

Este artigo tem por objetivo transmitir apontamentos sobre a norma contida no art. 1.147 do Código Civil de 2002, sem correspondência na legislação anterior. A pretensão não é exaurir o tema, mas definir os institutos essenciais para a adequada compreensão da cláusula de não restabelecimento, mediante referência não apenas à jurisprudência, mas também aos comercialistas mais referendados. Confia-se em que este estudo fornecerá ao leitor os

\footnotetext{
${ }^{1}$ Mestrando em Direito da Empresa e Atividades Econômicas pela Universidade do Estado do Rio de Janeiro UERJ; Pós-graduado em Direito Processual Civil pela Pontifícia Universidade Católica do Rio de Janeiro PUC-Rio; Pós-graduado em Direito Privado Patrimonial pela Pontifícia Universidade Católica do Rio de Janeiro - PUC-Rio; Bacharel em Direito pela Pontifícia Universidade Católica do Rio de Janeiro - PUC-Rio. E-mail: pedroplopes@hotmail.com
}

Revista Brasileira de Direito Empresarial | e-ISSN: 2526-0235| Porto Alegre | v. 4 | n. 2 | 
subsídios necessários para diferir conceitos por vezes confundidos, tais quais, o de aviamento e clientela, assim como o de sociedade empresarial e estabelecimento.

$\mathrm{Na}$ primeira parte, será desenvolvido um resumo sobre a evolução histórica da cláusula de não restabelecimento. O caminho percorrido pelo instituto até os dias atuais é relevante para que o interlocutor compreenda a sua origem e desenvolvimento, sobretudo porque nada dispunha a respeito o Código Civil de 1916, aprovado sob a vigência da Constituição Federal de 1981.

Na sequência, serão definidos os institutos inerentes à compreensão da norma, tais como o de "estabelecimento", "aviamento" e "clientela". Entender estes conceitos certamente proporcionará ao leitor ainda mais ferramentas para delimitar de maneira adequada a norma em evidência.

Estas definições serão sucedidas pelos apontamentos mais relevantes sobre a cessão do estabelecimento e as limitações dela decorrentes, sugeridas pelo legislador como forma de proteção ao fundamento e princípio constitucionais da livre iniciativa e livre concorrência, respectivamente.

Finalmente, considerando a relevância atribuída pelo legislador brasileiro aos precedentes judiciais, sobretudo após a entrada em vigor do Código de Processo Civil de 2015, serão avaliadas duas decisões dos tribunais superiores sobre o tema, assim como algumas outras julgadas recentemente pelos Tribunais de Justiça do Estado de São Paulo TJ-SP e do Rio de Janeiro - TJ-RJ.

Metodologia utilizada para desenvolver o trabalho partiu da análise dos principais institutos correlatos ao tema, legislação pertinente, ocorrência na prática da problemática, natureza e características das premissa e institutos descritos. O estudo ainda adotará o método hipotético-dedutivo de pesquisa, partindo da análise das normas previstas no ordenamento jurídico, interpretação funcional do instituto, sua aplicação pela doutrina e pela jurisprudência, produzindo conclusão com base nas premissas adotadas no material coligido. Como fontes, serão utilizadas a pesquisa bibliográfica, a partir da análise de precedentes sobre o tema proposto.

\section{A EVOLUÇÃo HiSTÓRICA DA CLÁUSULA DE NÃo RESTABELECIMENTO}


Aprovado sob a vigência da Constituição Federal de $1891^{2}$, o Código Civil de 1916 não continha dispositivo legal expresso que disciplinasse o restabelecimento concorrencial do alienante do estabelecimento ${ }^{3}$. Na oportunidade, nem mesmo o debate travado 3 anos antes entre Rui Barbosa e José Xavier Carvalho de Mendonça serviu de inspiração para os legisladores.

Em 1913, os referidos advogados protagonizaram interessante duelo diante dos ministros do Supremo Tribunal Federal $-\mathrm{STF}^{4}$. O primeiro defendia que a cessão ou a transferência do estabelecimento empresarial não abrangia a sua clientela por não integrar o fundo de comércio, exceto se o instrumento firmado entre as partes dispusesse em sentido contrário. $\mathrm{O}$ segundo divergia, sustentando que a cessão da clientela seria inerente àquela espécie de negócio.

Concluíram os magistrados, como narra o Professor Ricardo Negrão (2008, p 95), não ser presumível a renúncia ao direito de restabelecimento, daí porque a renúncia deveria decorrer expressamente do contrato firmado entre as partes, com a devida restrição temporal:

\begin{abstract}
Entretanto, lê-se no acórdão que tese diversa resultou vitoriosa: a renúncia ao exercício de determinado ramo de comércio ou indústria não se presume, sendo necessário, para sua validade, estar expressa em cláusula escrita e restrita ao tempo, espaço e objeto. Além disso, diz o acórdão, a freguesia de estabelecimento industrial recai sobre a transformação operada na matéria-prima, pela natureza especial do produto e não pelo local do estabelecimento ou pelas relações pessoais com o comerciante. Adotou-se, por essa histórica decisão, a possibilidade de restabelecimento, consagrando a ideia de que a obediência às cláusulas de interdição de concorrência somente poderia ser admitida entre alienante e adquirente de fundo empresarial se expressas em documento firmado pelos contratantes.
\end{abstract}

Apesar do precedente, durante todo o século anterior, a doutrina majoritária defendeu que a não concorrência por parte do alienante constituía cláusula implícita, inerente ao

\footnotetext{
${ }^{2}$ Sobre a Constituição de 1891, principalmente para que o leitor compreenda o cenário histórico em que o Código Civil de 1916 foi instituído, confiram-se as lições de Inocêncio Mártires Coelho: "Esgotado, por causas diversas, o regime monárquico, sobreveio a República - menos por crença nas suas virtudes e mais por descrença nas instituições monárquicas - e, com ela, a instauração de uma nova ordem constitucional, cujo ponto de partida foi o Decreto n.1, de 15.11.1889, da lavra de Rui Barbosa, que a proclamou, provisoriamente, como forma de governo da nação brasileira a República Federativa e estabeleceu as normas pelas quais se deviam reger os Estados Federais." (COELHO, Inocêncio Mártires. Curso de Direito Constitucional. Gilmar Ferreira Mendes; Inocêncio Mártires Coelho; Paulo Gustavo Gonet Branco (coord.). 5. ed. rev. e atual. São Paulo: Saraiva, 2010. p. 228)

${ }^{3}$ O Código Comercial de 1850 também nada dispunha a respeito.

${ }^{4}$ Trata-se da famosa disputa travada entre Conde Álvares Penteado, a Companhia Nacional de Tecidos da Juta e a Companhia Paulista de Aniagem.
}

Revista Brasileira de Direito Empresarial | e-ISSN: 2526-0235| Porto Alegre | v. 4 | n. 2 |

p. $01-19$ | Jul/Dez. 2018 
trespasse $^{5}$, sob o fundamento de que a turbação privaria o adquirente da coisa vendida, no todo ou em parte ${ }^{6}$.

Da mesma forma, o legislador italiano previu que o alienante do estabelecimento deveria abster-se, durante o prazo de 5 anos da transferência, de iniciar nova atividade cujo objeto, localização ou outras circunstâncias, seja suscetível de enganar a clientela do estabelecimento alienado. É o que dispõe expressamente o artigo 2.557 do Código Civil, de 4 de abril de $1942^{7}$.

A redação serviu de inspiração para o legislador brasileiro, que, com mais de meio século de atraso, aprovou o Código Civil, Lei $\mathrm{n}^{\circ}$ 10.406, de 10 de janeiro de 2002, contendo no seu bojo o art. 1.147, segundo o qual: "não havendo autorização expressa, o alienante do estabelecimento não pode fazer concorrência ao adquirente, nos cinco anos subseqüentes à transferência."

\section{ESTABELECIMENTO, AVIAMENTO E CLIENTELA}

O artigo 1.147 do Código Civil demonstra o cuidado do legislador em adotar como regra geral a impossibilidade de concorrência entre o alienante e o adquirente do estabelecimento. Como protagonista da redação, portanto, o estabelecimento definido pelo

\footnotetext{
${ }^{5}$ Assim explicou Arnoldo Wald: "Todavia, mesmo diante da inexistência da cláusula, a doutrina nacional majoritária defendia o entendimento de que a não-concorrência por parte do alienante constitui cláusula implícita, inerente ao negócio de trespasse (...)" (WALD, Arnoldo. Comentários ao Novo Código Civil. v. XIV: livro II, do direito de empresa. Sálvio de Figueiredo Teixeira (coord.). Rio de Janeiro: Forense, 2005. p. 750).

6 "Conseguintemente, ao vendedor não é lícito, sem autorização do comprador, fundar estabelecimento em que lhe possa retirar toda ou parte da clientela. Esta turbação por parte do vendedor importaria privar o comprador, no todo ou em parte, da coisa vendida." (MENDONÇA, J. X. Carvalho de. Tratado de direito comercial brasileiro. 4 ed. Rio de Janeiro, Freitas Bastos, 1946, v. 1. p. 169)

${ }^{7}$ Art. 2557 Divieto di concorrenza

Chi aliena l'azienda deve astenersi, per il periodo di cinque anni dal trasferimento, dalliniziare una nuova impresa che per l'oggetto, l'ubicazione o altre circostanze sia idonea a sviare la clientela dell'azienda ceduta $(2125,2596)$

Il patto di astenersi dalla concorrenza in limiti più ampi di quelli previsti dal comma precedente è valido, purché non impedisca ogni attività professionale dell'alienante. Esso non può eccedere la durata di cinque anni dal trasferimento.

Se nel patto è indicata una durata maggiore o la durata non e stabilita, il divieto di concorrenza vale per il periodo di cinque anni dal trasferimento.

Nel caso di usufrutto o di affitto dell'azienda il divieto di concorrenza disposto dal primo comma vale nei confronti del proprietario o del locatore per la durata dell'usufrutto o dell'affitto.

Le disposizioni di questo articolo si applicano alle aziende agricole solo per le attività ad esse connesse (2135), quando rispetto a queste sia possibile uno sviamento di clientela.
}

Revista Brasileira de Direito Empresarial | e-ISSN: 2526-0235| Porto Alegre | v. 4 | n. 2 |

p. $01-19$ | Jul/Dez. 2018 
legislador como "todo complexo de bens organizado, para exercício da empresa, por empresário, ou por sociedade empresária"8.

Para a maior parte da doutrina, o conceito de estabelecimento comercial (ou fundo de comércio $^{9}$ ) não estaria restrito ao local em que o empresário desenvolve a sua atividade, na forma do art. 966 do Código Civil ${ }^{10}$, devendo ser caracterizado como universalidade de bens ${ }^{11}$, como bem definiu Patrícia Scardini Silveira Schuckert, em dissertação de mestrado:

\begin{abstract}
Predomina, hoje, na doutrina brasileira o entendimento de que o estabelecimento empresarial tem natureza jurídica de uma universalidade de fato. Essa universalidade é formada pela vontade do seu titular, o empresário, que organiza, como um conjunto, os diversos elementos componentes do estabelecimento, tendo em vista o exercício de uma determinada atividade. Nesse caso, como os elementos que compõem o estabelecimento formam uma unidade, em virtude da destinação que lhes foi dada pelo seu titular, trata-se de uma universalidade de fato, tal como definido expressamente na norma do artigo 90 do Código Civil. ${ }^{12}$
\end{abstract}

Especificamente sobre o art. 90 do Código Civil ${ }^{13}$, explica Leonardo Honorato Costa (2013, p. 157) que "a norma legal, claramente, disse menos do que gostaria (lex minus dixit quam voluit) autorizando uma interpretação extensiva. Uma interpretação adequada do dispositivo seria, portanto, 'constitui universalidade de fato a pluralidade de elementos singulares que, pertinentes à mesma pessoa, tenham destinação unitária'”.

Seja como for, o conceito de estabelecimento não se confunde com a definição de empresa, considerada esta mais ampla do que aquele e constituída por uma realidade abstrata

\footnotetext{
${ }^{8}$ Art. 1.142. Considera-se estabelecimento todo complexo de bens organizado, para exercício da empresa, por empresário, ou por sociedade empresária.

9 "Registro que não é correto tomar por sinônimos 'estabelecimento empresarial' e 'fundo de empresa'." (COELHO, Fábio Ulhoa. Curso de direito comercial. São Paulo: Saraiva, 1999. v. 1., p. 93)

${ }_{10}$ Art. 966. Considera-se empresário quem exerce profissionalmente atividade econômica organizada para a produção ou a circulação de bens ou de serviços. Parágrafo único. Não se considera empresário quem exerce profissão intelectual, de natureza científica, literária ou artística, ainda com o concurso de auxiliares ou colaboradores, salvo se o exercício da profissão constituir elemento de empresa.

11 "É de se ter em mente que o "estabelecimento empresarial", ou seu sinônimo "fundo de comércio" (expressão utilizada pelos franceses como fonds de commerce e pelos italianos como aziendas), não se restringe ao local da atividade do empresário, abrangendo, também, a forma de organização da atividade econômica desenvolvida e os equipamentos utilizados para o exercício da empresa. Tal definição consagra 'o entendimento doutrinário dominante de que o estabelecimento é uma universalidade de bens' (POSTIGLIONE, 2006, p. 22).” (ANDRADE, Luiz Gustavo de. Transferência do Estabelecimento Empresarial. Conhecimento Interativo, São José dos Pinhais, PR, v. 3, n. 1, p. 47-81, jan./jun. 2007. p. 47)

${ }^{12}$ SCHUCKERT, Patrícia Scardini Silveira. A Proibição de Concorrência na Alienação do Estabelecimento e sua Aplicação no Direito da Empresa à Luz da Constituição de 1988 e do Código Civil, 2006. Dissertação de Mestrado apresentada ao Programa de Pós-Graduação Stricto Sensu em Direito da Faculdade de Direito de Campos.

${ }^{13}$ Art. 90. Constitui universalidade de fato a pluralidade de bens singulares que, pertinentes à mesma pessoa, tenham destinação unitária.
}

Revista Brasileira de Direito Empresarial | e-ISSN: 2526-0235| Porto Alegre | v. 4 | n. 2 |

p. $01-19$ | Jul/Dez. 2018 
de fatores ${ }^{14}$. Não por outro motivo, aponta Rubens Requião constituir o estabelecimento instrumento do exercício empresarial, necessário para aparelhar a atividade (1998, p. 244) ${ }^{15}$.

A distinção é relevante para que o leitor compreenda não constituir o aviamento ${ }^{16}$ elemento da empresa, mas sim atributo inerente ao estabelecimento comercial ${ }^{17}$, este sujeito à influência de diferentes variáveis, que, conjuntamente, determinarão a aptidão de cada um para gerar mais ou menos lucros ${ }^{18}$.

A clientela, por seu turno, constitui um dos fatores do aviamento (NEGRÃO, 2008, p. 86), definida por Oscar Barreto Filho (1998, p. 171) como "conjunto de pessoas que, de fato, mantém com o estabelecimento relações continuadas de procura de bens e de serviços", representando ainda "objeto de direito assim como o aviamento, ao qual se atribui um valor econômico de notória relevância e que é protegido de forma direta, mediante a tutela do estabelecimento e a repressão às práticas desleais" (MORAES, 2001, p. 118).

\section{A CESSÃO DO ESTABELECIMENTO E O TRESPASSE}

\footnotetext{
14“Mostra-se oportuno, e desde logo necessário, trazer a diferenciação existente entre estabelecimento e empresa. O conceito de empresa é mais amplo, pois a empresa constitui-se em uma realidade abstrata. O estabelecimento, por sua vez, é um dos elementos integrantes da empresa; o instrumento pelo qual se dá o exercício da atividade empresarial." (ANDRADE, Luiz Gustavo de. op. cit., p. 48)

15 "O fundo de comércio ou estabelecimento comercial é o instrumento da atividade do empresário. Com ele o empresário comercial aparelha-se para exercer sua atividade. Forma o fundo de comércio a base física da empresa, constituindo um instrumento da atividade empresarial. O Código italiano o define como o complexo dos bens organizados pelo empresário, para o exercício da empresa." (REQUIÃO. Rubens. Curso de direito comercial. 23. ed. São Paulo: Saraiva, 1998. v. 1., p. 244)

${ }^{16} \mathrm{O}$ aviamento representa um acréscimo de valor, algo que se junta à soma dos valores dos elementos singularmente considerados, em virtude da sua organização, na unidade técnica do estabelecimento, que os torna aptos a produzir novas riquezas. É um sobrevalor que surge com a criação da casa comercial e perdura até a sua extinção. Não existe estabelecimento sem aviamento. O aviamento é, portanto, um interesse econômico relevante, que recebe proteção legal em função do estabelecimento, e sua existência é perceptível quanto ocorre o trespasse, momento em que se atribui ao aviamento uma valoração. (MORAES, Maria Antonieta Lynch de. O Trespasse: a alienação do estabelecimento empresarial e a cláusula de não restabelecimento. Revista dos Tribunais. Ano 90. Outubro de 2001 - Vol. 792. p. 118)

${ }^{17} \mathrm{O}$ aviamento existe no estabelecimento, com a beleza, a saúde ou a honradez existem na pessoa humana, a velocidade no automóvel, a fertilidade no solo, constituindo qualidades incindíveis dos entes a que se referem. $\mathrm{O}$ aviamento não existe como elemento separado do estabelecimento, e, portanto, não pode constituir em si e por si objeto autônomo de direitos, suscetível de ser alienado, ou dado em garantia. (BARRETO FILHO, Oscar. Teoria do Estabelecimento Comercial. 2. Ed. São Paulo: Saraiva, 1998, p. 171)

${ }^{18}$ Cada estabelecimento empresarial possui um aviamento, maior ou menor, sendo o resultado de um conjunto de vários fatores de ordem material ou imaterial, os quais conferem ao estabelecimento a capacidade ou aptidão de gerar lucros. Os ingleses o chamam de goodwill of a trade e o definem como 'the value of a business establishment over and above its cash assets and material property', ou seja, o valor de um estabelecimento mercantil acima ou abaixo de seu ativo disponível e de seus bens materiais. Trata-se, pois, de valor e não de coisa." (NEGRÃO, Ricardo. op. cit. p. 83/84).
}

Revista Brasileira de Direito Empresarial | e-ISSN: 2526-0235| Porto Alegre | v. 4 | n. 2 |

p. $01-19$ | Jul/Dez. 2018 
Para Ricardo Tepedino (2006, p. 62), o estabelecimento constitui objeto de direito e, por este motivo, somente a sua titularidade pode ser cedida ou trespassada a terceiros ${ }^{19}$. Ainda de acordo com as suas lições, o trespasse não se confundiria com a cessão, porque o seu objeto seria constituído pela transferência de um complexo unitário de bens instrumentais que servem à atividade empresarial, concluindo que, nestas hipóteses, a própria empresa, compreendida como atividade organizada para a produção ou a circulação de bens ou de serviços (definição do artigo 966 do Código Civil), também seria transferida com o estabelecimento.

Entretanto, é preciso ter cuidado ao interpretar a parte final desta última afirmativa. Afinal, como reconhecem a doutrina e a jurisprudência (confiram-se, a respeito, as decisões referidas na próxima parte), a transferência do estabelecimento não se confunde com a cessão de quotas de uma sociedade (PEGORINI, 2015) ${ }^{20}$, nem com o negócio jurídico que instrumentaliza a alienação do controle de uma sociedade anônima (SILVA, 2016) ${ }^{21}$.

\footnotetext{
19 "Podendo ser tomado como objeto de direito, a titularidade do estabelecimento pode ser transferida a outrem. É o que se consuma chamar de trespasse, ou cessão de estabelecimento, sendo, como preconizava, J.X. Carvalho de Mendonça, preferível a primeira denominação, eis que cessão remete propriamente à transferência de direitos. Como bem adverte Oscar Barreto Filho, só se pode falar em trespasse do estabelecimento comercial 'quando o negócio se refere ao complexo unitário de bens instrumentais que servem à atividade empresarial, necessariamente caracterizado pela existência do aviamento objetivo'. Daí ser possível concluir que a empresa, compreendida como atividade organizada para a produção, a mais das vezes é transferida juntamente com o estabelecimento que lhe serve de plataforma para o exercício dessa atividade. (TEPEDINO, Ricardo. O Trespasse para Subsidiária (Drop Down). In: Direito Societário e a Nova Lei de Falências e Recuperação de Empresas. CASTRO, Rodrigo R. Monteiro de; ARAGÃO, Leandro dos Santos (coord.). São Paulo: Quartier Latin, 2006. p. 62.)

${ }^{20}$ Citando o Professor Fábio Ulhoa Coelho, Matheus Bisotto Pegorini, para quem: "Imprescindível frisar com clareza que o trespasse não se confunde com a cessão de quotas sociais de uma sociedade limitada ou alienação do controle de uma sociedade anônima. Segundo Fábio Ulhoa Coelho, 'são institutos jurídicos bastante distintos, embora com efeitos econômicos bastante idênticos, na medida em que são meios de transferência da empresa.' No trespasse, o objeto da venda é o estabelecimento comercial, ou seja, a reunião de bens corpóreos e incorpóreos organizados de maneira racional, cuja questão conceitual foi abordada, enquanto na cessão de quotas ou da alienação do controle a venda é referente à participação societária" (PEGORINI, Matheus Bizotto. O estabelecimento empresarial e a responsabilidade do adquirente e do alienante no trespasse. IOBRepertório de Jurisprudência: Civil, Processual, Penal e Comercial. São Paulo. v.3. n.19. p.715-711. out. 2015. p. 86).

21 "A redação do artigo 1.147 do Código Civil é clara ao limitar sua aplicação apenas ao trespasse. Além disso, a transferência de estabelecimento comercial e a alienação de ações ou quotas de sociedades empresárias, embora semelhantes com relação aos seus efeitos econômicos, envolvem institutos jurídicos completamente distintos. A obrigação de não concorrência, por sua natureza restritiva, não pode ser interpretada de forma extensiva. Desse modo, não deve ser considerada adequada a aplicação do artigo 1.147 do Código Civil a negócios jurídicos que envolvam a transferência do controle de sociedades empresárias." (SILVA, Ricardo Villela Mafra Alves da. Aplicação do artigo 1.147 do Código Civil à alienação do controle de sociedades empresárias. Disponibilizado em: http://www.publicadireito .com.br/artigos/?cod=c51a02c186f00636. Acessado no dia 03 de janeiro de 2017)
}

Revista Brasileira de Direito Empresarial | e-ISSN: 2526-0235| Porto Alegre | v. 4 | n. 2 |

p. $01-19$ | Jul/Dez. 2018 
O fato é que a clientela, caracterizada como fator do aviamento e coisa incorpórea indissociável do estabelecimento, diferentemente deste último, não pode figurar sozinha como protagonista de um contrato autônomo, que vise única e exclusivamente a sua cessão ou trespasse $^{22}$.

Chegar a essa conclusão, contudo, não significa afirmar que a clientela transferida ao adquirente por meio da aquisição do estabelecimento não será resguardada pelo ordenamento jurídico brasileiro, principalmente porque, em muitas oportunidades, a compra do estabelecimento ocorre justamente para aquisição indireta da carteira de clientes já constituída.

Justamente por isso, respaldado pelo fundamento e princípio constitucionais da livre iniciativa (art. $\left.4^{\mathrm{o}}, \mathrm{IV}\right)^{23}$ e da livre concorrência (art. 170, IV) ${ }^{24}$, respectivamente, o legislador brasileiro tutelou a coisa cedida ou trespassada, mediante a vedação da competição entre alienante e comprador pelos 5 anos seguintes à transferência do estabelecimento ${ }^{25}$.

A um primeiro olhar, a norma pode até parecer incoerente, pois veda, ainda que temporariamente, que o alienante constitua novo estabelecimento para concorrer com o

\footnotetext{
22 "A clientela não é um elemento separável do estabelecimento, que, como coisa incorpórea, possa formar objeto de contrato autônomo. Quando se verifica o trespasse do estabelecimento, um efeito natural do negócio, que se contém na vontade normal das partes, é o de manter a integridade do fundo, com todos os elementos e atributos que o individuam e caracterizam, inclusive na organização e os demais fatores do aviamento, a fim de conservar para o adquirente a mesma capacidade objetiva de obtenção de lucros. Para atingir esse objetivo normal e desejado pelas partes, entende-se que, implicitamente, o alienante se obriga a não abrir concorrência ao adquirente, em circunstâncias que ensejem o desvio da clientela do estabelecimento transferido." (BARRETO FILHO, Oscar. op. cit. p. 251/252)

23 "A liberdade de iniciativa consubstancia-se na regra: 'a todos é assegurado o livre exercício de qualquer atividade econômica, independentemente de autorização governamental, salvo nos casos previstos em lei."” (CARVAlHOSA, Modesto. Comentários ao Código Civil. Antônio Junqueira de Azevedo (coord.). São Paulo: Saraiva, 2003. p.649/650).

${ }^{24}$ Já a livre concorrência, como manifestação da liberdade de iniciativa, consiste na prorrogativa que têm os agentes econômicos atuantes no mercado de adotar todas as iniciativas licitas que lhes estiverem disponíveis para cooptar a clientela. A livre concorrência é manifestação natural de uma economia de mercado, sendo salutar esperado que as empresas concorram entre si, forcando umas as outras a um constante aprimoramento de seus métodos organizacionais e produtivos, à redução gradativa dos seus custos e a uma busca permanente pela melhora das condições oferecidas aos seus consumidores." (idem. p. 650)

25 "2. Tutela de concorrência. Não se considera a clientela elemento do estabelecimento empresarial, mas seu atributo (v. comentários ao art. 1.142). Em outras palavras, não dispõe o empresário ou sociedade empresarial de suposto direito à clientela (nesse sentido: Oscar Barreto Filho, Teoria, p. 241; Paulo Miguel, "O estabelecimento", p.49; e João Eunápio Borges, Curso, p. 198). O ordenamento, no entanto, busca tutelá-la por meio da vedação à concorrência desleal, prevendo comportamentos ilícitos e criminosos que de alguma forma visem à usurpação da clientela legitimamente conquistada pelo empresário (v. L. 9.279/1996, art. 195, III). Além da sanção criminal, os responsáveis sujeitam-se a ações cíveis de ressarcimento das perdas e danos advindos por tais atos, ainda que sem previsão legal específica (arts. 207 e 209)" (TEPEDINO, Gustavo; BARBOZA, Heloisa Helena; BODIN, Maria Celina. Código civil interpretado conforme a Constituição da República - vol. III. Rio de Janeiro: Renovar, 2011. p. 371).
}

Revista Brasileira de Direito Empresarial | e-ISSN: 2526-0235| Porto Alegre | v. 4 | n. 2 |

p. $01-19$ | Jul/Dez. 2018 
comprador, fato que geraria mais competição, a causar vantagens para os consumidores e para o mercado de uma maneira geral (externalidade positiva).

A formação de um ambiente concorrencial eficiente, porém, não pode basear-se em políticas liberais irrestritas ${ }^{26}$. Essa construção depende da constituição de mecanismos efetivos de proteção à concorrência desleal, assim entendida por Carlos Alberto Bittar (1989, p. 37) como: "todo ato de concorrente que, valendo-se de força econômica de outrem, procura atrair indevidamente sua clientela", sendo possível "dizer que existe concorrência desleal em toda a ação de concorrente que se aproveita indevidamente de criação ou de elemento integrante do aviamento alheio, para captar, sem esforço próprio, a respectiva clientela" (IDEM). A definição é cuidadosamente comentada por Modesto Carvalhosa (2003, p. 650), que sustenta haver duas formas distintas de violação à livre concorrência:

\begin{abstract}
A primeira compreende tanto a concorrência desleal, reprimida no âmbito civil e penal, quanto a proibição de concorrência na transferência do estabelecimento empresarial, combatida somente no plano civil. Ambas envolvem apenas os interesses particulares dos empresários concorrentes, não prejudicando, em principio, outros agentes econômicos que se relacionem com o estabelecimento. Não comprometem, consequentemente, as estruturas da livre concorrência. Já a outra espécie de conduta anticoncorrencial, apurada e reprimida também no plano administrativo, por meio das entidades integrantes do sistema brasileiro de proteção da concorrência instituídas pela Lei n. 8.884/94, é chamada de infração à ordem econômica, pois compromete as estruturas da livre concorrência.
\end{abstract}

Nesse caso, pretendendo encaixar a vedação ao restabelecimento no âmbito civil, o jurista parece ignorar as referidas externalidades que o controle privado da concorrência desleal pode gerar, ainda que não sejam de simples aferição os resultados práticos da proibição de restabelecimento do alienante, prevista art. 1.147 do Código Civil de 2002.

Prova contundente de que os efeitos desse dispositivo também operam consequências para o mercado é a posição dos autores brasileiros de que a cláusula de não concorrência estaria sujeita a limitações de tempo e escopo, para não ser considerada ofensiva à legislação antitruste em vigor, atualizada mediante a publicação da Lei $n^{\circ} 12.529$, de 30 de novembro de $2011^{27}$.

\footnotetext{
${ }^{26}$ Confira-se, a respeito, a definição do princípio da eficiência, por Calixto Salomão Filho, em obra dedicada exclusivamente ao direito concorrencial brasileiro (SALOMÃO FILHO, Calixto. Direito Concorrencial. São Paulo: Malheiros, 2013. p. 234 e ss).

27 "2.194 Fica claro que a cláusula de não-concorrência, lícita na forma do artigo 1.147 conforme se depreende dos casos sujeitos à análise dos órgãos do Sistema Brasileira de Defesa da Concorrência, está sujeita a limitações
}

Revista Brasileira de Direito Empresarial | e-ISSN: 2526-0235| Porto Alegre | v. 4 | n. 2 |

p. $01-19$ | Jul/Dez. 2018 
Não por outra razão, em 09 de dezembro de 2009, o Conselho Administrativo de Defesa da Concorrência - CADE regulamentou a matéria, estabelecendo expressamente no verbete $n^{\circ} 5$ de sua Súmula que seria "lícita a estipulação de cláusula de não-concorrência com prazo de até cinco anos da alienação de estabelecimento, desde que vinculada à proteção do fundo de comércio"28.

A esse respeito, ainda veda a jurisprudência do CADE que as partes estabeleçam cláusulas irrestritas de não-concorrência, isto é, sem apontar a extensão geográfica dos efeitos da limitação, evitando que a concorrência seja afetada em locais diferentes daquele em que se deu a alienação do estabelecimento ${ }^{29}$.

Sobre o tema, mais especificamente a respeito do elemento pessoal da cláusula de não restabelecimento, Marcelo Andrade Féres (2010) chega a afirmar "mostrar-se conveniente o arrastamento da vedação de concorrência sobre outras pessoas" 30 , como, por exemplo, nas hipóteses em que as partes pretendem vedar a participação dos administradores da sociedade empresária em atividade desenvolvida pelo estabelecimento cedido ao adquirente.

Em linhas gerais, portanto, conclui-se que a norma extraída do art. 1.147 do Código Civil de 2002, constitucionalmente pautada no fundamento da livre iniciativa e no princípio da livre concorrência, foi estabelecida não apenas para garantir que o alienante do estabelecimento não se arvore dentro do prazo de 5 anos do aviamento da empresa e da clientela da coisa vendida, como também para assegurar mecanismos mais eficientes de

de tempo e de escopo, para que não se considere como ofensiva à Lei no 8.884/94." (WALD, Arnoldo. op. cit.. p. 756).

${ }^{28}$ Disponibilizado no endereço eletrônico: http://www.cade.gov.br/assuntos/normas-e-legislacao/sumu las-do cade/sumula-no-5-publicada-no-d-o-u-de-09-12-2009/view. Acessado no dia 02 de janeiro de 2018.

${ }^{29}$ A cláusula de não concorrência, no que tange à sua extensão geográfica, não se encontra em consonância com entendimentos anteriores do plenário do $\mathrm{CADE}$, que limita os efeitos desse tipo de cláusula à área afetada pela operação. [...] Voto pela aprovação do ato, condicionada à adequação da dimensão geográfica da cláusula de não concorrência à região metropolitana de São Paulo/SP" (BRASIL. Conselho Administrativo de Defesa da Concorrência. AC 08012.008939/2008-51. Relator: Conselheiro Fernando de Magalhães Furlan. Data do Acórdão: 16/03/2009)

${ }^{30}$ Quanto ao elemento pessoal, em princípio, ele diz respeito às partes signatárias do trespasse. Entretanto, conforme os dados do caso concreto, pode mostrar-se conveniente o arrastamento da vedação de concorrência sobre outras pessoas. Imagine-se, por exemplo, a hipótese de alienação de estabelecimento de sociedade empresária; o instrumento de trespasse pode atribuir aos seus administradores, bem como ao sócio controlador, a obrigação de não fazer concorrência ao trespassário. A propósito, G. RIPERT e R. ROBLOT citam diversos arestos franceses, através dos quais a interdição de concorrência alcança terceiros, ainda que não haja cláusula expressa. Isso ocorre com herdeiros ou com dirigentes de sociedades, como no exemplo acima." (FERÉS, Marcelo Andrade. A cláusula (legal) de interdição da concorrência no trespasse do estabelecimento empresarial. Disponibilizado no endereço: http://www.pos.direito.ufmg.br/rbepdocs/10 1137158.pdf. Acessado em 03 de janeiro de 2018)

Revista Brasileira de Direito Empresarial | e-ISSN: 2526-0235| Porto Alegre | v. 4 | n. 2 |

p. $01-19$ | Jul/Dez. 2018 
proteção aos personagens do mercado, dentre os quais se inserem, principalmente, os consumidores.

\section{ABORDAGEM JURISPRUDENCIAL DA CLÁUSULA DE NÃO RESTABELECIMENTO}

Dada à importância que a dogmática processual mais atualizada confere aos precedentes judiciais, principalmente depois da entrada em vigor do Código de Processo Civil de 2015, que atribuiu eficácia normativa a determinadas orientações jurisprudenciais ${ }^{31}$, dedica-se um título exclusivo deste trabalho à evolução jurisprudencial da cláusula de não restabelecimento.

A primeira vez em que os tribunais superiores brasileiros se manifestaram sobre a cláusula de não restabelecimento foi nos autos do já mencionado processo em que figuravam como partes: o Conde Álvares Penteado e a Companhia Nacional de Tecidos da Juta, contra a Companhia Paulista de Aniagem. Naquela oportunidade, os ministros concluíram que renúncia ao direito de restabelecimento deveria decorrer expressamente do contrato firmado entre as partes.

Superado esse entendimento pela norma contida no art. 1.147 do Código Civil de 2002, em decisão proferida no dia 20 de março de 2014, o Superior Tribunal de Justiça - STJ reconheceu a validade de cláusula de não restabelecimento, destacando que o referido mecanismo de privação da concorrência só se mostraria abusivo caso não fosse estabelecido por prazo determinado, dado que o sistema jurídico pátrio não se coadunaria com ausência de limitações temporais ${ }^{32}$ :

[...] 2. É válida a cláusula de "não restabelecimento" no tocante ao seu objeto, rejeitando-se a alegada violação ao art. 166, II e VII, do Código Civil de 2002, pois é regra comum nos negócios jurídicos que envolvem transmissão de direitos sobre estabelecimentos, amplamente utilizada no cotidiano empresarial. Insta mencionar que o CC/2002 inovou ao trazer expressamente, no seu art. 1.147, a "cláusula de não restabelecimento".

\footnotetext{
31 "A nova feição da atividade jurisdicional redesenhou o Direito processual. De um lado, estrutura-se um sistema de precedentes judiciais, em que se reconhece eficácia normativa a determiandas orientações da jurisprudência. A proliferação das 'súmulas' dos tribunais e a consagração da 'súmula vinculante do STF' (art. 103-A, CF/1988 são exemplos mais ostensivos.” (DIDIER JR., Fredie. Curso de direito processual civil: introdução ao direito processual civil, parte geral e processo de conhecimento. $17^{\mathrm{a}}$ Ed. Salvador: Jus Podivm, 2015. V1. P. 50).

${ }^{32}$ BRASIL. Superior Tribunal de Justiça. Quarta Turma. REsp 680.815/PR, Rel. Ministro Raul Araújo. Julgado em 20/03/2014.
}

Revista Brasileira de Direito Empresarial | e-ISSN: 2526-0235| Porto Alegre | v. 4 | n. 2 |

p. $01-19$ | Jul/Dez. 2018 
3. O art. 421 de CC/2002 positivou o princípio da função social dos contratos como limitador da liberdade de contratar, inexistindo violação a essa norma, no estabelecimento da cláusula de "não restabelecimento", usual na realidade empresarial para coibir a concorrência desleal.

4. Mostra-se abusiva a vigência por prazo indeterminado da cláusula de "não restabelecimento", pois o ordenamento jurídico pátrio, salvo expressas exceções, não se coaduna com a ausência de limitações temporais em cláusulas restritivas ou de vedação do exercício de direitos. Assim, deve-se afastar a limitação por tempo indeterminado, fixando-se o limite temporal de vigência por cinco anos contados da data do contrato, critério razoável adotado no art. 1.147 do CC/2002. [...]

Em outra hipótese, por ocasião do julgamento do recurso especial $\mathrm{n}^{\circ}$ 978.200/PR ${ }^{33}$, embora não tenha mencionado expressamente o art. 1.147, a Terceira Turma do STJ entendeu que não depende de comprovação efetiva do dano a reparação por ato de concorrência desleal que importem em desvio de clientela, haja vista que o fato por si só já representaria perda patrimonial à vítima, como explicitou a ministra relatora Nancy Andrighi.

No plano estadual, a jurisprudência do Tribunal de Justiça de São Paulo (TJSP) costuma adotar os entendimentos de que: (a) a cláusula de interdição não se aplica ao instrumento de compra e venda de quotas da sociedade, dado que este não se confunde com o contrato de trespasse ${ }^{34}$; (b) a vedação à concorrência deve ser limitada temporal e geograficamente ${ }^{35}$; (c) não seria necessária a comprovação de constituição de nova pessoa

\footnotetext{
33 "Direito comercial e processual civil. Recurso especial. Concorrência desleal e desvio de clientela. Embargos declaratórios. Omissão. Ausência. Reexame de provas. Inadmissibilidade. Inépcia da inicial. Inocorrência. Danos materiais. Comprovação. Presunção - Ausentes os vícios do art. 535 do CPC, rejeitam-se os embargos de declaração. - É inadmissível o reexame de fatos e provas em recurso especial. - Verificada a existência de causa de pedir, não há reconhecer-se a inépcia da inicial na presente hipótese. - O art. 209 da Lei 9.279/96 autoriza a reparação por danos materiais advindos de atos de concorrência desleal que importem desvio de clientela pela confusão causada aos consumidores. - A reparação não está condicionada à prova efetiva do dano, pois os atos de concorrência desleal e o consequente desvio de clientela provocam, por si sós, perda patrimonial à vítima. Recurso especial não provido.” (BRASIL. Superior Tribunal de Justiça. Terceira Turma. REsp 978200/PR. Rel. Min. Nancy Andrighi. Julgado em 19/11/2009)

34 “APELAÇÃO. AÇÃO INDENIZATÓRIA. Abertura de estabelecimento comercial no mesmo ramo de atividade e nas proximidades do estabelecimento que as partes eram sócias. Alienação de cotas sociais. Inexistência de cláusula de interdição de concorrência no instrumento de venda e compra de cotas sociais. Impossibilidade de aplicação por analogia da regra prevista no art. 1.147 do CC. Cessão de cotas sociais que não se confunde com trespasse. CONCORRÊNCIA DESLEAL. Ausência de provas de que a ré pratica conduta ilícita. Indenização indevida. HONORÁRIOS ADVOCATÍCIOS SUCUMBENCIAIS RECURSAIS. Majoração em razão do resultado do julgamento. Sentença mantida. Recurso improvido." (SÃO PAULO. Tribunal de Justiça. $1^{\text {a }}$ Câmara Reservada de Direito Empresarial. Apelação no 1009709-49.2016.8.26.0562. Rel. Des. Hamid Bdine. Julgado em 16/08/17)

35 "Ação de resolução de contrato de trespasse de estabelecimento comercial. Sentença que manteve obrigação de não concorrência, a despeito de revelia da compradora. Apelação da autora. Cláusula de não concorrer que deve ser limitada espacial e temporalmente. Análise do dispositivo contratual que revela ausência de circunscrição espacial. Obrigação que proibia a criação de filiais, isto é, que a autora adotasse método de organização da atividade empresarial semelhante ao do negócio alienado. Ministrar aulas particulares em residência não consiste em violação de cláusula de não concorrer com escola de idiomas, examinada a avença à luz do disposto no art. 1.147 do Código Civil. Reforma da sentença recorrida. Apelação a que se dá provimento."
}

Revista Brasileira de Direito Empresarial | e-ISSN: 2526-0235| Porto Alegre | v. 4 | n. 2 |

p. $01-19$ | Jul/Dez. 2018 
jurídica para demonstrar a violação ao dever de não competição ${ }^{36}$; e (d) a despeito do consolidado entendimento doutrinário sobre o tema, a norma contida no art. 1.147 do Código Civil de 2002 não se aplicaria aos contratos de cessão de estabelecimento firmados antes da entrada em vigor da nova Lei $^{37}$.

Já o Tribunal de Justiça do Rio de Janeiro (TJRJ) em alguns casos adotou o entendimento de que: (a) a prática de ato caracterizado como concorrência desleal poderia ser qualificado como violação a dever anexo do contrato (lealdade contratual) ${ }^{38}$; e (b) a coexistência na mesma praça de estabelecimentos cujos titulares exploram o mesmo ramo comercial não configura, por si só, ato de concorrência desleal previsto no art. 1.147 do Código Civil, pois não havia nos autos comprovação do emprego de práticas ardilosas ou ilícitas capazes de gerar dano ao concorrente ${ }^{39}$.

(SÃO PAULO. Tribunal de Justiça. $1^{\text {a }}$ Câmara Reservada de Direito Empresarial. Apelação $\mathrm{n}^{\circ}$ 100009812.2015.8.26.0464. Rel. Des. Cesar Ciampolini. Julgado em 21/02/17)

36 "CONTRATO DE TRESPASSE. Obrigação legal de não concorrência durante determinado prazo. Loja de materiais de construção. Resolução. Admissibilidade. Prosseguimento do alienante no mesmo ramo empresarial e âmbito territorial em estabelecimento comercial pertencente à sua irmã. Violação positiva do contrato. Ausência de empresa em nome do alienante. Irrelevância. A vedação do art. 1.147 é ampla, à concorrência de modo geral, e não apenas à constituição de pessoa jurídica concorrente. Violação da cláusula de nãoconcorrência e dos deveres anexos de lealdade e de informação. Sentença reformada. Recurso provido." (SÃO PAULO. Tribunal de Justiça. $1^{\text {a }}$ Câmara Reservada de Direito Empresarial. Apelação $\mathrm{n}^{\circ}$ 401001716.2013.8.26.0602. Rel. Des. Francisco Loureiro. Julgado em 1\%/03/16)

37 “CONCORRÊNCIA DESLEAL - AÇÃO DE INDENIZAÇÃO - Cerceamento de defesa Inocorrência Matéria exclusivamente de direito (art. 330, I, do CPC) - Improcedência Contrato de compra e venda firmado entre as partes, anterior ao advento do Novo Código Civil Inaplicabilidade da regra do art. 1.147 à hipótese Inexistência ainda de cláusula de restrição (o que afasta o nexo causal a amparar a pretensão indenizatória aqui discutida) Precedentes - Improcedência corretamente decretada Sentença mantida Recurso improvido." (SÃO PAULO. Tribunal de Justiça. $8^{a}$ Câmara de Direito Privado. Apelação no 0001180-91.2007.8.26.0362. Rel. Des. Salles Rossi. Julgado em 26/10/11)

38 “APELAÇÃO. RESPONSABILIDADE CIVIL. CÓDIGO CIVIL, ARTIGO 1.147 E LEI N. ${ }^{\circ}$ 9.279/96, ARTIGO 209. CONCORRÊNCIA DESLEAL CONFIGURADA. VIOLAÇÃO A DEVER ANEXO DO CONTRATO: LEALDADE CONTRATUAL. PRINCÍPIO DA BOA-FÉ OBJETIVA. DANO MORAL CONFIGURADO. Alegação de não comprovação dos fatos constitutivos dos direitos dos autores que não prospera. Demonstração documental e confissão da atuação caracterizadora da concorrência desleal. Uso indevido de cheque em nome da pessoa jurídica autora. Uso de linha telefônica veiculada sob anúncio em páginas amarelas e afins divulgando a atividade de retirada de entulho e limpeza de rua com a finalidade de captação de clientela. Atividade desenvolvida pelo Apelante que é a mesma exercida pelo Primeiro Apelado, sociedade cujas cotas foram pelo Apelante transferidas aos demais Apelados. Dano moral configurado, tendo que superou um pouco a capacidade do ofensor em suportá-lo. Redução de $\mathrm{R} \$ 10.000,00$ (dez mil reais) para $\mathrm{R} \$$ 5.000,00 (cinco mil reais), atendendo melhor ao princípio da razoabilidade e atingido o efeito compensatório. Decisão mantida. RECURSO A QUE SE DÁ PARCIAL PROVIMENTO." (RIO DE JANEIRO; Tribunal de Justiça. $5^{\text {a }}$ Câmara Cível. Apelação no 0011045-54.2004.8.19.0002. Rel. Des. Teresa de Andrade Castro Neves. Julgado em 06.10.09)

${ }_{39}$ "APELAÇÃO CÍVEL. DIREITO EMPRESARIAL. CONCORRÊNCIA DESLEAL. ALEGAÇÃO AUTORAL DE QUE A SAÍDA DO SEGUNDO RÉU DA SOCIEDADE EMPRESÁRIA EXPLORADORA DO RAMO ESTÉTICO (SALÃO DE BELEZA), COM A ABERTURA DE NOVO ESTABELECIMENTO COMERCIAL NA MESMA PRAÇA, E UTILIZAÇÃO DE ESTRATÉGIAS COMERCIAIS DA ANTIGA EMPRESA, ESTARIA LHE GERANDO PERDA DE CLIENTES E PREJUÍZOS FINANCEIROS.

Revista Brasileira de Direito Empresarial | e-ISSN: 2526-0235| Porto Alegre | v. 4 | n. 2 |

p. $01-19$ | Jul/Dez. 2018 
Sobre a decisão referida no primeiro item do parágrafo anterior (item "a"), relevante citar as conclusões alcançadas por Tânia Bahia Carvalho Siqueira(2014, pp. 235-6), em pesquisa sobre o contrato de trespasse, analisado sob a perspectiva dos deveres de conduta. A autora destaca que desta espécie de relação jurídica também advêm obrigações laterais, nos seguintes termos:

\begin{abstract}
Do contrato de trespasse, especificamente falando, advêm deveres, como o de informar e o dei ser informado acerca das circunstância em torno da negociação (há informações que somente o trespassante detém), não se admitindo sejam as informações falseadas, omitidas ou deficientes para a eficaz declaração de vontade; o dever de não quebrar a confidencialidade sobre documentos e informações estratégicas da sociedade detentora do estabelecimento; o dever de o trespassante concorrer com o adquirente do estabelecimento no prazo de até cinco anos, explorando a mesma ou similar atividade na mesma praça onde é explorada a empresa. As partes têm asseguradas, a partir dos princípios da boa-fé objetiva e da função social do contrato, a garantia de fruir plenamente o resultado socioeconômico do contrato. Qualquer conduta que viole essa premissa, base do negócio jurídico, será considerada violação a um dever latera de conduta. Os deveres de conduta possuem caráter contratual e irradiam limitações e vedações às condutas das partes, sob pena de implicar inadimplemento do contrato com todas as suas consequências daí advindas (indenizações, multas pela rescisão). A satisfação das legítimas expectativas das partes confere ao mercado a tão desejada segurança do tráfego negocial, dái justificando-se a tutela aos princípios da confiança de boa-fé. Essa é a realidade do direito brasileiro estampada em vários posicionamentos doutrinários e em decisões judiciais.

Enfim, o caminho percorrido a partir da base teórica (o conhecimento acerca do instituto jurídico), passando pela dimensão prática (os aspectos contratuais), culminando com o olhar crítico acerca do tema (a realidade conforme posta nos Tribunais), nos permite concluir que, além do cumprimento das prestações, o integral adimplemento dos contratos empresariais exige, como comando cogente, a
\end{abstract}

SENTENÇA DE IMPROCEDÊNCIA. APELO DA AUTORA. A COEXISTÊNCIA, NA MESMA PRAÇA, DE ESTABELECIMENTOS COMERCIAIS QUE EXPLORAM O MESMO RAMO COMERCIAL NÃO CONFIGURA, POR SI SÓ, CONCORRÊNCIA DESLESAL. HIPÓTESE DOS AUTOS QUE NÃO SE AMOLDA AO ARTIGO 1.147 DO CÓDIGO CIVIL. PARA A CARACTERIZAÇÃO DA CONCORRÊNCIA DESLEAL NECESSÁRIO SE FAZ QUE HAJA UMA CONDUTA QUE CONTRARIE OS PRINCÍPIOS NORTEADORES DO DUELO DE MERCADO, POR MEIO DE PRÁTICAS ARDILOSAS OU ILÍCITAS CAPAZES DE GERAR DANO AO CONCORRENTE, DEVENDO A ANÁLISE SE DAR CASUISTICAMENTE. ENTENDIMENTO DO COLENDO STJ E DESTA CORTE. CONJUNTO PROBATÓRIO CARREADO AOS AUTOS DEMONSTRA QUE O RÉU/APELADO ATUA COMO CABELEIREIRO NO BAIRRO DE BOTAFOGO HÁ MAIS DE 15 ANOS, POSSUINDO CLIENTELA FIEL QUE O VEM ACOMPANHANDO POR TODOS ESSES ANOS. NATUREZA DA ATIVIDADE DESENVOLVIDA, CUJA REFERÊNCIA É O PRÓPRIO PROFISSIONAL E O TRABALHO POR ELE DESENVOLVIDO. FIXAÇÃO DE PREÇOS MENORES, DIMINUIÇÃO DE FATURAMENTO E PERDA DE CLIENTES, SEM A DEMONSTRAÇÃO DE CONDUTA DE MÁ-FÉ, NÃO CONFIGURA CONCORRÊNCIA DESLEAL. EVIDÊNCIAS DE QUE A MAIOR PARTE DOS CLIENTES DA EMPRESA RECORRENTE ERA ORIUNDA DO TRABALHO DESENVOLVIDO PELO SEGUNDO APELADO. APLICAÇÃO DO PRINCÍPIO DA LIVRE CONCORRÊNCIA. ARTIGO 170 , IV DA CF/88. INTERFERÊNCIA MÍNIMA DO ESTADO. INTELIGÊNCIA DA SÚMULA VINCULANTE Nº. 49. PRECEDENTES DESTA EGRÉGIA CÂMARA. CONDUTA DESLEAL NÃO CONFIGURADA. DESPROVIMENTO DO RECURSO.” (RIO DE JANEIRO. Tribunal de Justiça. $13^{a}$ Câmara Cível. Apelação no 0197485-20.2011.8.19.0001. Rel. Des. Francisco de Assis Pessanha Filho. Julgado em 16.8.17)

Revista Brasileira de Direito Empresarial | e-ISSN: 2526-0235| Porto Alegre | v. 4 | n. 2 |

p. $01-19$ | Jul/Dez. 2018 
observância dos deveres laterais refletidos em retidão de comportamento que conduza ao resultado socioeconômico daqueles que celebram o contrato de trespasse.

Pelo que se pode perceber, para além da interpretação literal do art. 1.147 do Código Civil, há uma imensidade de hipóteses fáticas que podem ocasionar dúvidas ou até mesmo aplicações equivocadas da norma jurídica. Por exemplo, na segunda decisão (item “b”), em que o TJRJ, em ativismo judicial, considerou que somente caracterizaria ato de concorrência desleal aqueles praticados com dolo (culpa lato sensu), muito embora o dispositivo não exija o emprego de qualquer requisito além da comprovação da conduta para a aplicação do comando legal.

\section{CONCluSÃo}

Pelo exposto, a primeira conclusão a que se chega é a de que a cláusula de não restabelecimento passou a ser disciplinada apenas pelo art. 1.047 do Código Civil de 2002, muito embora já houvesse sido objeto de relevante embate judicial travando entre Rui Barbosa e José Xavier Carvalho de Mendonça.

Até o advento da nova legislação prevalecia o entendimento de que a não concorrência por parte do alienante constituía cláusula implícita, inerente ao trespasse, sob o fundamento de que a turbação privaria o adquirente.

Sobre o estabelecimento empresarial, classificado pela maior parcela da doutrina especializada como universalidade de fato, é importante que o instituto seja diferenciado dos conceitos de empresa, clientela e aviamento, sobretudo porque a fixação adequadas dos conceitos permite que o intérprete adote soluções mais adequadas no plano fático. Por exemplo, aquela mediante a qual o TJ-SP julgou que a cláusula de interdição não se aplicava ao instrumento de compra e venda de quotas da sociedade, dada à impossibilidade de confusão entre essa e o objeto do contrato de trespasse do estabelecimento.

As considerações seguintes foram sobre os objetivos pretendidos pelo legislador ao disciplinar o instituto no art. 1.147 do Código Civil de 2002. Constitucionalmente pautada no fundamento da livre iniciativa e no princípio da livre concorrência, a norma foi estabelecida para garantir que o alienante do estabelecimento não se arvore dentro do prazo de 5 anos do aviamento da empresa e da clientela da coisa vendida, assim como para assegurar 
mecanismos mais eficientes de proteção aos personagens do mercado, dentre os quais se inserem, principalmente, os consumidores.

A evolução jurisprudencial do instituto é notória. Sobre diversas hipóteses que envolvem o instituto já se manifestaram os dois importantes tribunais estaduais brasileiros. Igualmente o STJ, que não hesitou em reconhecer, acertadamente, a validade de cláusula de não restabelecimento, destacando que o referido mecanismo de privação da concorrência só se mostraria abusivo caso não fosse estabelecido por prazo determinado, dado que o sistema jurídico pátrio não se coadunaria com ausência de limitações temporais.

\section{REFERÊNCIAS}

ANDRADE, Luiz Gustavo de. Transferência do Estabelecimento Empresarial. Conhecimento Interativo, São José dos Pinhais, PR, v. 3, n. 1, p. 47-81, jan./jun. 2007.

BARRETO FILHO, Oscar. Teoria do Estabelecimento Comercial. 2. Ed. São Paulo: Saraiva, 1998.

BITTAR, Carlos Alberto. Teoria e Prática da Concorrência Desleal. São Paulo, Saraiva, 1989.

BRASIL. Conselho Administrativo de Defesa da Concorrência. Disponibilizado no endereço eletrônico: http://www.cade.gov.br/assuntos/norm as-e-legislacao/sumulas-do-cade/sumulano-5-publicada-no-d-o-u-de-09-12-2009/view. Acessado em 15/12/2017.

BRASIL. Conselho Administrativo de Defesa da Concorrência. AC 08012.008939/2008-51.

Relator: Conselheiro Fernando de Magalhães Furlan. Data do Acórdão: 16/03/2009.

BRASIL. Superior Tribunal de Justiça. Quarta Turma. REsp 680.815/PR, Rel. Ministro Raul Araújo. Julgado em 20/03/2014.

BRASIL. Superior Tribunal de Justiça. Terceira Turma. REsp 978.200/PR. Rel. Min. Nancy Andrighi. Julgado em 19/11/2009.

Revista Brasileira de Direito Empresarial | e-ISSN: 2526-0235| Porto Alegre | v. 4 | n. 2 |

p. $01-19$ | Jul/Dez. 2018 
AC 08012.008939/2008-51. Relator: Conselheiro Fernando de Magalhães Furlan.

Data do Acórdão: 16.03.2009.

CARVAlhoSA, Modesto. Comentários ao Código Civil: parte especial: do direito de empresa. v 13. Coord. Antônio Junqueira de Azevedo. São Paulo: Saraiva, 2003.

COELHO, Fábio Ulhoa. Curso de direito comercial. São Paulo: Saraiva, 1999. v. 1.

COELHO, Inocêncio Mártires. Curso de Direito Constitucional. Gilmar Ferreira Mendes; Inocêncio Mártires Coelho; Paulo Gustavo Gonet Branco (coord.). 5. ed. rev. e atual. São Paulo: Saraiva, 2010.

COSTA, Leonardo Honorato. Nova Concepção do Contrato de Trespasse. Revista dos Tribunais. Ano 102. Outubro de 2013 - Vol. 929

DIDIER JR., Fredie. Curso de direito processual civil: introdução ao direito processual civil, parte geral e processo de conhecimento. 17 ed. Salvador: Jus Podivm, 2015. V1.

FERÉS, Marcelo Andrade. A cláusula (legal) de interdição da concorrência no trespasse do estabelecimento empresarial. In. Revista Brasileira de Estudos Políticos. Belo Horizonte, n. 101, p. 137-158, jul./dez. 2010. Disponibilizado no endereço: http://www.pos.direito.ufmg.br/rbepdocs/10 1137158.pdf.

MENDONÇA, J. X. Carvalho de. Tratado de direito comercial brasileiro. 4 ed., Rio de Janeiro, Freitas Bastos, 1946, v. 1.

MORAES, Maria Antonieta Lynch de. O Trespasse: a alienação do estabelecimento empresarial e a cláusula de não restabelecimento. Revista dos Tribunais. Ano 90. Outubro de 2001 - Vol. 792.

NEGRÃO, Ricardo. Manual de direito comercial e de empresa. v 1.6 ed. rev. e atual. São Paulo: Saraiva, 2008.

Revista Brasileira de Direito Empresarial | e-ISSN: 2526-0235| Porto Alegre | v. 4 | n. 2 | p. $01-19$ | Jul/Dez. 2018 
PEGORINI, Matheus Bizotto. O estabelecimento empresarial e a responsabilidade do adquirente e do alienante no trespasse. IOB-Repertório de Jurisprudência: Civil, Processual, Penal e Comercial. São Paulo. v.3. n.19. p.715-711. out. 2015.

REQUIÃO. Rubens. Curso de direito comercial. 23. ed. São Paulo: Saraiva, 1998.

RIO DE JANEIRO; Tribunal de Justiça. 5 $5^{\text {a }}$ Camara Cível. Apelação no 0011045 54.2004.8.19.0002. Rel. Des. Teresa de Andrade Castro Neves. Julgado em 06/10/09.

RIO DE JANEIRO. Tribunal de Justiça. 13 ${ }^{\mathrm{a}}$ Câmara Cível. Apelação $\mathrm{n}^{\circ}$ 019748520.2011.8.19.0001. Rel. Des. Francisco de Assis Pessanha Filho. Julgado em 16/08/17.

SALOMÃO FILHO, Calixto. Direito Concorrencial. São Paulo: Malheiros, 2013.

SÃO PAULO. Tribunal de Justiça. $1^{\text {a }}$ Câmara Reservada de Direito Empresarial. Apelação ${ }^{\circ}$ 1009709-49.2016.8.26.0562. Rel. Des. Hamid Bdine. Julgado em 16/08/17.

SÃO PAULO. Tribunal de Justiça. $1^{\text {a }}$ Câmara Reservada de Direito Empresarial. Apelação ${ }^{\circ}$ 1000098-12.2015.8.26.0464. Rel. Des. Cesar Ciampolini. Julgado em 21/02/17.

SÃO PAULO. Tribunal de Justiça. $1^{\text {a }}$ Câmara Reservada de Direito Empresarial. Apelação no 4010017-16.2013.8.26.0602. Rel. Des. Francisco Loureiro. Julgado em 1\%/03/16.

SÃO PAULO. Tribunal de Justiça. 8ª Câmara de Direito Privado. Apelação nº 000118091.2007.8.26.0362. Rel. Des. Salles Rossi. Julgado em 26/10/11.

SCHUCKERT, Patrícia Scardini Silveira. A Proibição de Concorrência na Alienação do Estabelecimento e sua Aplicação no Direito da Empresa à Luz da Constituição de 1988 e do Código Civil, 2006. Dissertação de Mestrado apresentada ao Programa de Pós-Graduação Stricto Sensu em Direito da Faculdade de Direito de Campos. 
SILVA, Ricardo Villela Mafra Alves da. Aplicação do artigo 1.147 do Código Civil à alienação do controle de sociedades empresárias. Disponibilizado no endereço: http://www.publicadireito .com.br/artigos/?cod=c51a02c186f00636.

SIQUEIRA, Tânia Bahia Carvalho. O contrato de trespasse sob a perspectiva dos deveres de conduta. Revista de Direito Privado. São Paulo. v.15. n.58. p.181-238. abr./jun. 2014.

TEPEDINO, Gustavo; BARBOZA, Heloisa Helena; BODIN, Maria Celina. Código civil interpretado conforme a Constituição da República. v. 3. Rio de Janeiro: Renovar, 2011.

TEPEDINO, Ricardo. O Trespasse para Subsidiária (Drop Down). In: Direito Societário e a Nova Lei de Falências e Recuperação de Empresas. Coord. CASTRO, Rodrigo R. Monteiro de; ARAGÃO, Leandro dos Santos. São Paulo: Quartier Latin, 2006.

WALD, Arnoldo. Comentários ao Novo Código Civil, v. XIV: livro II, do direito de empresa; coordenador: Sálvio de Figueiredo Teixeira - Rio de Janeiro: Forense, 2005. 